\title{
Trauma admissions to the Intensive care unit at a reference hospital in Northwestern Tanzania
}

\author{
Phillipo L Chalya ${ }^{1 *}$, Japhet M Gilyoma ${ }^{1 \dagger}$, Ramesh M Dass ${ }^{2 \dagger}$, Mabula D Mchembe ${ }^{3 \dagger}$, Michael Matasha ${ }^{4 \dagger}$, \\ Joseph B Mabula ${ }^{1 \dagger}$, Nkinda Mbelenge $^{2 \dagger}$ and William Mahalu ${ }^{5+}$
}

\begin{abstract}
Background: Major trauma has been reported to be a major cause of hospitalization and intensive care utilization worldwide and consumes a significant amount of the health care budget. The aim of this study was to describe the characteristics and treatment outcome of major trauma patients admitted into our ICU and to identify predictors of outcome.
\end{abstract}

Methods: Between January 2008 and December 2010, a descriptive prospective study of all trauma admissions to a multidisciplinary intensive care unit (ICU) of Bugando Medical Centre in Northwestern Tanzania was conducted.

Results: A total of 312 cases of major trauma were admitted in the ICU, representing $37.1 \%$ of the total ICU admissions. Males outnumbered females by a ratio of 5.5:1. Their median age was 27 years. Trauma admissions were almost exclusively emergencies (95.2\%) and came mainly from the Accident and Emergency (60.6\%) and Operating room (23.4\%). Road traffic crash (RTC) was the most common cause of injuries affecting $70.8 \%$ of patients. Two hundred fourteen patients (68.6\%) required surgical intervention. The overall ICU length of stay (LOS) for all trauma patients ranged from 1 to 59 days (median $=8$ days). The median ICU length of hospital stay (LOS) for survivors and nonsurvivors were 8 and 5 days respectively. $(P=0.002)$. Mortality rate was $32.7 \%$. Mortality rate of trauma patients was significantly higher than that of all ICU admissions (32.7\% vs. $18.8 \%, P=0.0012$ ). According to multivariate logistic regression analysis, multiple injuries, severe head injuries and burns were responsible for a longer mean ICU stay $(P<$ 0.001) whereas admission Glasgow Coma Score $<9$, systolic blood pressure $<90 \mathrm{mmHg}$, injury severity core $>16$, prolonged duration of loss of consciousness, delayed ICU admission (0.028), the need for ventilatory support and finding of space occupying lesion on computed tomography scan significantly influenced mortality $(P<0.001)$.

Conclusion: Trauma resulting from road traffic crashes is a leading cause of intensive care utilization in our hospital. Urgent preventive measures targeting at reducing the occurrence of RTCS is necessary to reduce ICU trauma admissions in this region. Improved pre- and in-hospital care of trauma victims will improve the outcome of trauma patients admitted to our ICU.

Keywords: Intensive care unit, trauma admissions, prevalence, injury characteristics, outcome, Tanzania

\section{Background}

Major or severe trauma constitutes a global public health problem and poses diagnostic and therapeutic challenges to trauma, orthopaedic and general surgeons practicing in developing countries [1]. Major trauma contributes significantly to high morbidity, mortality and long-term

\footnotetext{
* Correspondence: drphillipoleo@yahoo.com

+ Contributed equally

'Department of Surgery, Weill-Bugando University College of Health

Sciences, Mwanza, Tanzania

Full list of author information is available at the end of the article
}

disabilities worldwide [1,2]. In developing countries including Tanzania, injuries in general are increasing due to increase in urbanization, motorization, civil violence, wars and criminal activities [3]. In these countries, major trauma remains a major cause of hospitalization and intensive care utilization and consumes a significant amount of the health care budget [4]. In Bugando Medical Centre, major trauma is the single most common reason for admission to the Intensive Care Unit (ICU) and is it associated with substantial emotional, physical and financial burden on community and hospital resources.

\section{Biomed Central}


Major trauma is often life threatening and usually presents as an emergency, requiring either immediate surgical intervention or intensive care or both $[4,5]$. The Intensive Care Unit is a specialized area where facilities for the critically ill or severely injured patients are concentrated and where the level of care and supervision is considerably more sophisticated than in the ordinary ward [4-6]. Worldwide, intensive care unit requires a vast use of up to date resources such as advanced monitors, organ support equipments and highly skilled staff. This however, often taxes the most buoyant health systems even of the developed nations [4,6]. In most developing nations where there are several financial constraints resulting from poor funding of the health care generally and the ICU specifically, there is often a limit to the availability and specialization of this form of care [6]. Besides allocation of resources, intensive care also demands a tremendous amount of time and effort on behalf of the medical and nursing staff to treat and improve survival of the critically ill patients. It therefore follows that the role of the ICU must be justified wherever it exists [5,6]. The allocation of ICU facilities when financial resources are limited is determined by cost/ benefit and patient outcome [6,7]. Admission of patients with poor prognosis and/or prolonged use of the ICU facility results in other patients with a better prognosis being denied care; many of these die as a result [7].

Despite continued advances in intensive care unit technology and the availability of sophisticated interventions for the treatment of critically ill or severely injured patients, major trauma patients continue to die in the ICU [6,7]. Identification of factors responsible for this state of affairs is of paramount in order to improve the outcome these patients. Understanding the magnitude of the problem and characterizing the patterns of injury in these patients is important in planning programmes targeted at preventing their occurrence and subsequently reduce ICU admissions. There is paucity of published data on ICU trauma admissions in our environment despite large number of trauma admissions to our ICU. This study was conducted to describe the characteristics and treatment outcome of major trauma patients admitted into our ICU and to identify predictors of outcome.

\section{Methods}

\section{Study design and setting}

Between January 2008 and December 2010, a descriptive prospective study was conducted in the ICU of Bugando Medical Centre (BMC). BMC is found in Mwanza city in the Northwestern Tanzania along the shore of Lake Victoria. It is one of the four tertiary referral hospitals in the country and serves as a teaching hospital for Weill- Bugando University College of Health Sciences (WBUCHS) and other paramedics. It has a bed capacity of 1000 and provides services to approximately 13 million people from six regions namely Mwanza, Kagera, Mara, Shinyanga, Kigoma and Tabora. The hospital has a 12-bed adult and 10-bed paediatric multi-disciplinary Intensive Care Unit (ICU) which is headed by a consultant anesthesiologist and run by trained ICU nurses. The ICU provides services to all patients (trauma and non-trauma, medical and surgical) requiring advanced airway support, mechanical ventilation, hemodynamic support, and electronic monitoring which are usually not available in the open wards in our hospital. The majority of trauma patients admitted in the ICU come from the Accident and Emergency (A \& E) department, operating theatre, wards and others come from other peripheral hospitals.

\section{Study subjects}

The study subjects included all patients with traumatic injuries severe enough to warrant ICU admission and who consented for the study. Patients who were readmitted to the ICU during the same hospital stay were excluded from the study. A total of 334 patients were recruited for the study and screened for inclusion criteria. Of these, 314 patients met the inclusion criteria and the remaining 20 patients did not. Patients who met the inclusion criteria were requested to consent for the study before being enrolled in the study. Two patients refused to consent for the study. Thus, 312 patients were enrolled in the study.

All study patients were initially resuscitated according to ATLS and treated according to ICU protocols. The severity of injury was assessed by the injury severity score (ISS) and the Glasgow coma score (GCS). An initial systolic blood pressure (SBP) on each patient was also recorded on admission. Data were collected used a questionnaire. Data administered in the questionnaire included details of demographic profile, causes of injury, injury characteristics, injury severity using Glasgow Coma scale (GCS) and injury severity score (ISS), treatment offered, complications, ICU length of stay (LOS), mortality and patient disposal. ICU length of stay. Patients were followed up till death or discharge from the ICU.

\section{Statistical data analysis}

Data collected was analyzed using SPSS software version 15.0. Data was summarized in form of proportions and frequent tables for categorical variables. Continuous variables were summarized using means, median, mode and standard deviation. $\chi 2$-test was used to test for significance of associations between the predictor and outcome variables in the categorical variables. Student t-test was used to test for significance of associations between the predictor and outcome variables in the continuous variables.. Significance was defined as a p-value of $<0.05$. 
Multivariate logistic regression analysis was used to determine predictor variables that are associated with outcome.

\section{Variable definitions}

Road traffic crash was defined as accident which took place on the road between two or more objects one of which must be any kind of a moving vehicle.

Patients were divided into two groups according to the timing of ICU admission on arrival. Patients who were admitted to the ICU immediately on arrival were classified as "immediate admission group" and patients who had to wait for ICU admission due to bed unavailability or any other reason were classified as "delayed admission group". The nature of injury was classified as "intentional injuries" defined as injuries that occur as a result of interpersonal or self-inflicted violence and "unintentional injuries" defined as injuries that occur accidentally. ICU length of stay was arbitrary dichotomized into two groups' i. e. $\leq 14$ days and $>14$ days respectively. An ICU length of stay of $>14$ days was considered as prolonged hospital stay.

\section{Ethical consideration}

Ethical approval to conduct the study was obtained from the WBUCHS/BMC joint institutional ethic review committee before the commencement of the study. Patients who met the inclusion criteria or their relative were requested to sign a written informed consent before being enrolled into the study.

\section{Results}

There were a total of 312 trauma admissions to the ICU during the period under study, representing $37.1 \%$ (312/ $841)$ of the total ICU admissions. There were 264 ( $84.6 \%)$ males and females were 48 (15.4\%) with a males to female ratio of 5.5:1 compared with 1.2:1 for the total ICU admissions. Their ages ranged from 4 years to 71 years (median 27 years). Trauma admissions were almost exclusively emergencies (95.2\%) and came mainly from the Accident and Emergency (60.6\%) and Operating Room/Post Anaesthesia Care Unit (23.4\%). (Table 1)

The majority of the injuries were unintentional in 232 (74.4\%) patients. Intentional injuries were recorded in sixty (19.2\%) of cases and the remaining twenty $(6.4 \%)$ patients were cases of indeterminate intent. Road traffic crush was the most common cause of injuries affecting $70.8 \%$ of patients (Table 2).

One hundred and fifty-two (68.8\%) of RTCs were related to motorcycle injuries affecting motorcyclists (93, 61.2\%), passengers (40, 26.3\%) and pedestrian $(19,12.5 \%)$.

The head/neck and musculoskeletal (extremities) regions were commonly affected accounting for $95.5 \%$ and $34.6 \%$ of cases respectively (Table 3 ). Isolated injuries occurred in $208(66.7 \%)$ patients while $104(33.3 \%)$ patients had multiple injuries. Soft tissue injuries (i.e.
Table 1 Demographic and clinical characteristics of the ICU trauma admissions

\begin{tabular}{|c|c|c|}
\hline Study variable & Trauma admission & Total admission \\
\hline Number (N/\%) & $312(37.1)$ & $841(100)$ \\
\hline Sex (Male: Female ratio) & 5.5: 1 & $1.2: 1$ \\
\hline Median age (in years) & 27 & 30 \\
\hline Modal age group (years) & $21-30$ & $31-40$ \\
\hline \multicolumn{3}{|l|}{ Source of admission (N/\%) } \\
\hline${ }^{\circ} \mathrm{A} \& \mathrm{E}$ department & $189(60.6)$ & $301(35.8)$ \\
\hline${ }^{\circ} \mathrm{OR} / \mathrm{PACU}$ & $73(23.4)$ & $385(45.8)$ \\
\hline - Wards & $33(10.3)$ & $132(15.7)$ \\
\hline${ }^{\circ}$ Other hospital s & $17(5.7)$ & $22(2.6)$ \\
\hline - Unspecified & - & $1(0.1)$ \\
\hline \multicolumn{3}{|l|}{ Timing of admission } \\
\hline - Immediately & $111(35.6)$ & $365(43.4)$ \\
\hline • Delayed & $201(64.4)$ & $476(56.6)$ \\
\hline \multicolumn{3}{|l|}{ Type of admission (N/\%) } \\
\hline${ }^{\circ}$ Emergency & $297(95.2)$ & $573(68.1)$ \\
\hline${ }^{\circ}$ Elective & $15(4.8)$ & $268(31.9)$ \\
\hline \multicolumn{3}{|c|}{ Length of hospital stay (N/\%) } \\
\hline${ }^{\circ}<3$ days & $110(35.1)$ & $370(44.0)$ \\
\hline${ }^{\circ} \geq 3$ days & $202(64.9)$ & $471(56.0)$ \\
\hline Mortality rate (\%) & $102(32.7)$ & $158(18.8)$ \\
\hline
\end{tabular}

Keys: A \& E = Accident and Emergency; OR = Operating Room; PACU = Post Anaesthesia Care Unit

bruises, laceration, abrasion and contusions) and fractures (long bones, spines, pelvis, ribs, and skull) were the most common type of injuries accounting for $97.8 \%$ and $32.4 \%$ respectively (Table 4 ).

The ISS ranged from 16-56 with the mean of $19.74 \pm$ 9.81. The median was 17.00 . The mean GCS for patients with head injuries was $9.65 \pm 12.43$ (range $3-15$ ). The median GCS was 9. The majority of patients (172, 55.1\%) had admission SBP $<90 \mathrm{mmHg}$.

Of the 312 patients admitted to the ICU, 169 (54.2\%) patients were intubated and ventilated for a median of 7 days (range 1-32 days). Two hundred fourteen patients $(68.6 \%)$ required surgical intervention. Wound debridement, treatment of fractures and craniotomies were the commonest surgical procedures performed in 95.3\%, $43.5 \%$ and $14.5 \%$ of patients respectively (Table 5 ).

Table 2 Causes of injuries among ICU trauma victims

\begin{tabular}{lll}
\hline Cause of injury & Number of patients & Percentage \\
\hline Road traffic crush & 221 & 70.8 \\
Assaults & 36 & 11.5 \\
Falls & 12 & 3.8 \\
Burns & 9 & 2.9 \\
Other causes & 14 & 4.5 \\
Unknown & 20 & 6.4 \\
Total & $\mathbf{3 1 2}$ & $\mathbf{1 0 0}$ \\
\hline
\end{tabular}


Table 3 Site of injury among ICU trauma victims

\begin{tabular}{lll}
\hline Site of injury & Frequency & Percentage \\
\hline Head/neck & 298 & 95.5 \\
Musculoskeletal (extremities) & 108 & 34.6 \\
Chest & 82 & 26.3 \\
Abdomen & 62 & 19.9 \\
Pelvis & 14 & 4.5 \\
Spines & 8 & 2.6 \\
Genitalia & 4 & 1.3 \\
\hline
\end{tabular}

The overall ICU length of stay (LOS) for all trauma patients ranged from 1 to 59 days (median $=8$ days). The median ICU length of hospital stay (LOS) for survivors and non-survivors were 8 and 5 days respectively. These differences were statistically significant $(\mathrm{P}=$ $0.002)$.

Of the non-survivors, ten $(9.8 \%)$ died within 24 hours of ICU admission while twenty-four $(23.5 \%)$ died within 72 hours and six-eighty (66.7\%) died by the seventh ICU day. Of the survivors, thirty-two (15.2\%) were discharged to the wards within 72 hours, fifty-four $(25.7 \%)$ on the seventh day and one hundred and twenty-four (59.0\%) were discharged by the fourteenth day of ICU admission.

Analysis of outcome showed that 201(64.4\%) patients were transferred to the ward and $4 .(1.3 \%)$ patients were discharged home direct from the ICU. 3 patients $(1.0 \%)$ were referred to another tertiary institution and $1(0.3 \%)$ patient each absconded and left against medical advice respectively. A total of 102 patients died giving a mortality rate of $32.7 \%$. Mortality rate of trauma patients was significantly higher than that of all ICU admissions $(32.7 \%$ vs. $18.8 \%, \mathrm{P}=0.0012)$. According to multivariate logistic regression analysis, multiple injuries (O.R. $=2.34,95 \%$ C.I. (2.11-4.78), $\mathrm{P}=0.012$ ), severe head injuries [GCS $=3-8$ ] (O.R. $=0.54,95 \%$ C.I.(0.13-0.69), $\mathrm{P}=0.036)$ and burns (O. $\mathrm{R} .=4.92$, 95\%C.I. (2.43-8.15), $\mathrm{P}=0.017)$ were responsible for a longer (>14 days) ICU stay. Table 6 shows predictors of mortality according to univariate and multivariate analysis

\section{Discussion}

Number of ICU trauma admission

In this review, major trauma was the most common indication for admissions into our ICU (37.1\%), and

Table 4 Type of injuries among ICU trauma victims

\begin{tabular}{lll}
\hline Type of injury & Frequency & Percentage \\
\hline Soft tissue injuries (wounds) & 305 & 97.8 \\
Fractures & 101 & 32.4 \\
Craniocerebral injury & 67 & 21.5 \\
Visceral injury & 41 & 13.1 \\
Burns & 9 & 2.9 \\
Other injuries & 12 & 3.8 \\
\hline
\end{tabular}

Table 5 Type of surgical procedure performed $(\mathrm{N}=214)$

\begin{tabular}{lll}
\hline Surgical procedure & Frequency & Percentages \\
\hline Wound debridement & 204 & 95.3 \\
Treatment of fractures & 93 & 43.5 \\
Craniotomy (including elevation of skull & 31 & 14.5 \\
fracture) & & \\
Underwater seal drainage & 23 & 10.7 \\
Exploratory laparotomy & 17 & 7.9 \\
Tracheostomy & 12 & 5.6 \\
Eye surgery & 9 & 4.2 \\
Thoracotomy & 2 & 0.9 \\
\hline
\end{tabular}

represented $95.2 \%$ of emergency ICU admissions. This is higher than that reported in Jamaica and Nigeria by Mitchell et al [7] and Amanor-Boadu et al [8] respectively. ICU admission has been reported to be the most important factor in determining the ultimate outcome of critically ill and major trauma patients and to be successful requires adequate logistic and financial support, supporting disciplines (e.g. laboratories, radiology and surgery) and basic infrastructure such as good roads, regular electricity, water supply, availability of drugs by the patient's bedside and regular oxygen and compressed air supply [9]. Many of these are not regularly available in many low resource settings. It has been suggested that the inadequate medical and technical equipment of most ICUs in low resource economies substantially contribute to the high mortality rate of critically ill patients in such countries [10]. Facilities in our ICU are limited and obviously insufficient to cope with the number of patients being admitted.

\section{Demographic profile}

In agreement with previous studies [5-8,11], trauma patients admitted to our ICU were mostly young males, and had a better previous health status than most other ICU patients. However, the mortality was higher among them compared to the non-trauma patients. This group represents the economically active age and portrays an economic lost both to the family and the nation and the reason for their high incidence of traumatic injuries reflects their high activity levels and participation in highrisk activities. Male predominance in the present study is due to their increased participation in high-risk activities. The fact that the economically productive age-group were mostly involved calls for an urgent public policy response.

\section{Timing of ICU admission}

In keeping with other studies [12,13], our study has demonstrated an association between delay to ICU admission and higher mortality rate reflecting worsening of organ dysfunction during this period. Despite the care provided by ward healthcare workers while patients were 
Table 6 Predictors of mortality according to univariate and multivariate analysis

\begin{tabular}{|c|c|c|c|c|c|}
\hline \multirow[t]{2}{*}{ Independent (predictor)variable } & \multirow[t]{2}{*}{ Number of patients (N/\%) } & \multicolumn{2}{|c|}{ Univariate analysis } & \multicolumn{2}{|c|}{ Multivariate analysis } \\
\hline & & OR. $(95 \%$ C.I) & p-value & OR. $(95 \%$ C.I) & $\mathrm{p}$-value \\
\hline \multicolumn{6}{|l|}{ Age } \\
\hline$\leq 40$ & $202(64.7)$ & 1 & & 1 & \\
\hline$>40$ & $110(35.3)$ & $1.41(0.45-1.82)$ & 0.098 & $2.5(0.56-6.67)$ & 0.765 \\
\hline \multicolumn{6}{|l|}{ Sex } \\
\hline Male & 264(84.6) & 1 & & 1 & \\
\hline Female & $48(15.4)$ & $4.52(0.95-5.83)$ & 0.678 & $3.12(0.97-5.78)$ & \\
\hline \multicolumn{6}{|l|}{ Type of admission } \\
\hline Emergency & 297(95.2) & 1 & & 1 & \\
\hline Elective & $15(4.8)$ & $2.71(1.2-3.7)$ & 0.024 & $3.83(0.93-5.98)$ & 0.934 \\
\hline \multicolumn{6}{|l|}{ Timing of admission } \\
\hline Immediately & $111(35.6)$ & 1 & & 1 & \\
\hline Delayed & $201(64.4)$ & $2.93(2.22-8.45)$ & 0.003 & $3.43(2.26-7.91)$ & 0.028 \\
\hline \multicolumn{6}{|l|}{ Duration of LOC $(\mathrm{N}=214)$} \\
\hline$\leq 2$ hours & 72(33.6) & 1 & & 1 & \\
\hline$>$ hours & $146(68.2)$ & $2.23(1.89-7.98)$ & 0.000 & $0.34(0.12-0.78)$ & 0.004 \\
\hline \multicolumn{6}{|l|}{ ISS } \\
\hline$\leq 15$ & $2(0.6)$ & 1 & & 1 & \\
\hline$>15$ & $310(99.4)$ & $6.83(3.56-8.91)$ & 0.012 & $7.21(2.65-10.96)$ & 0.000 \\
\hline \multicolumn{6}{|l|}{ GCS } \\
\hline$<9$ & 192(61.5) & 1 & & & \\
\hline$\geq 9$ & $120(38.5)$ & $2.64(1.32-6.76)$ & 0.034 & $4.72(3.16-9.23)$ & 0.003 \\
\hline \multicolumn{6}{|l|}{ Admission SBP(mmHg) } \\
\hline$<90$ & $172(55.1)$ & 1 & & 1 & \\
\hline$\geq 90$ & 140(44.9) & $1.76(0.56-4.35)$ & 0.042 & $8.34(4.61-9.98)$ & 0.016 \\
\hline \multicolumn{6}{|l|}{ Need for ventilatory support } \\
\hline Yes & $169(54.2)$ & 1 & & 1 & \\
\hline No & $143(45.8)$ & $2.45(1.24-5.89)$ & 0.038 & $0.65(0.28-0.86)$ & 0.018 \\
\hline \multicolumn{6}{|c|}{ CT scan brain findings of SOL $(\mathrm{N}=122)$} \\
\hline Yes & $98(80.3)$ & 1 & & 1 & \\
\hline No & 24(19.7) & $0.77(0.23-0.98)$ & 0.000 & $3.53(2.23-6.97)$ & 0.015 \\
\hline
\end{tabular}

Abbreviations: O.R.= Odds ratio; C.I.= confidence interval; LOC = loss of consciousness; ISS = injury severity score; GCS = Glasgow coma scale; SBP = systolic blood pressure; $\mathrm{SOL}=$ space occupying space

waiting for ICU bed availability, these healthcare providers were not trained in critical care and were not as experienced in caring for ICU patients. Furthermore, hospital wards are neither designed nor staffed to provide extended longitudinal care for the critically ill patient. These patients have better outcomes when treated in ICUs with close and continuous involvement by critical care physicians $[14,15]$ and other data also show improved outcome when nurse-to-patient ratios in the ICUs are properly maintained [16]. Caring for critically ill patients outside the ICU may also imply an increased burden and high stress level experienced by hospital wards staff.

\section{Etiological pattern}

Road traffic crushes have been reported to be the commonest cause of ICU trauma admissions in most studies as supported by the present study $[7,8,11]$. This may be attributed to recklessness and negligence of the driver, poor maintenance of vehicles, driving under the influence of alcohol or drugs and complete disregard of traffic laws. In the present study, motorcycle injuries accounted for more than fifty percent of road traffic injuries and the motorcyclist constituted the majority of motorcycle injury victims. Findings from this study calls for urgent interventions targeting at reducing the occurrence of RTCs and subsequently reduce the incidence of ICU admissions in this region.

\section{Type of injuries}

The majority of our patients sustained head and musculoskeletal injuries, which is in keeping with previous studies [6-8,17-19]. Severe road traffic crashes are usually associated with significant head, musculoskeletal and multiple injuries, which explain why they are the leading cause of our ICU admissions, unlike in the wards. 


\section{Trauma scores}

The severity of injury on admission in the present study was assessed by the ISS and the GCS. Most validated ICU scoring system such as admission APACHE (Acute physiology age and chronic health evaluation) II Score were not used in this study because the majority of patients were transferred to the unit after initial stabilization from the Accident and Emergency unit. Also APACHE II score use parameters that require arterial blood gas analysis and other variables that we were unable to measure.

\section{Length of ICU stay}

In this study, survivors had a statistically significant longer LOS than non-survivors which is in agreement with other studies in developing countries $[7,8,20]$, but contrary to studies in developed countries which reported non-survivors staying longer and consuming more resources than survivors [10,21]. This difference in survival is probably due to a combination of factors including severity of injuries, poor pre-hospital care, lack of emergency medical services, and lack of appropriate diagnostic and therapeutic facilities including drugs for the care of these patients in the hospital and the ICU. These factors have been adequately addressed in developed nations.

\section{Mortality}

Our mortality rate $(32.7 \%)$ in the present study was higher than the mortality rate of $26.4 \%$ reported by Mitchel et al [7] in Jamaica but lower compared to mortality rate of $53.2 \%$ reported by Adenekan et al [20] in Nigeria. Higher mortality rate in our study may be attributed to severity of injuries, lack of advanced pre-hospital care in our setting, ineffective ambulance system for transportation of patients to hospitals, and lack of appropriate diagnostic and therapeutic facilities including drugs for the care of these patients in the hospital and the ICU. This observation calls for improved pre- and in-hospital care of trauma victims so as to improve the outcome of trauma patients admitted to our ICU.

\section{Study limitations}

Despite limitations of the study such as limited ICU space, unavailability of diagnostic tools (e.g. Computed tomography scan) and short-term study limited to ICU stay, this study demonstrated the impact of trauma admissions to our ICU.

\section{Conclusion}

Major trauma resulting from road traffic crashes is a leading cause of intensive care utilization in our hospital. Urgent preventive measures targeting at reducing the occurrence of RTCs is necessary to reduce the incidence of major trauma in this region and subsequently reduce ICU trauma admissions. These preventive measures include increased public education, enforcement of road safety rules, improvement in socioeconomic situation and employment opportunities in our country. Improved pre- and in-hospital care of trauma victims will improve the outcome of major trauma patients admitted to our ICU.

\section{Acknowledgements}

The authors acknowledge all those who provided care to our patients and those who provided support in preparation of this manuscript. Special thanks go to our research assistants for data collection and staff members of the ICU for their critical support in patient care.

\section{Author details}

'Department of Surgery, Weill-Bugando University College of Health Sciences, Mwanza, Tanzania. ${ }^{2}$ Department of Orthopaedics, Weill-Bugando University College of Health Sciences, Mwanza, Tanzania. ${ }^{3}$ Department of Surgery, Muhimbili University of Health and Allied Sciences, Dar Es Salaam, Tanzania. ${ }^{4}$ Department of Anaesthesia, Weill-Bugando University College of Health Sciences, Mwanza, Tanzania. ${ }^{5}$ Cardiothoracic unit, Weill-Bugando University College of Health Sciences, Mwanza, Tanzania.

\section{Authors' contributions}

PLC contributed in study design, literature search, data analysis, manuscript writing \& editing. JMG and RMD participated in study design, data analysis, manuscript writing \& editing. MDM participated in data analysis, manuscript writing \& editing. MM and JBM participated in data analysis and manuscript writing. WM supervised the study and contributed in data analysis, manuscript writing \& editing. All the authors read and approved the final manuscript.

\section{Competing interests}

The authors declare that they have no competing interests.

Received: 3 February 2011 Accepted: 24 October 2011

Published: 24 October 2011

\section{References}

1. Hofman K, Primack A, Keusch G, Hrynkow S: Addressing the growing burden of trauma and injury in low- and middle-income countries. Am J Public Health 2005, 95:13-7.

2. Park K: Accidents. In In Textbook of Social and Preventive Medicine.. 17 edition. Edited by: Park K. Jabalpur: Banarsidas Co; 2000:304-5.

3. Museru LM, Leshabari MT: Road traffic Accidents in Tanzania: A 10-year epidemiological Appraisal. East Central Afr J Surg 2002, 7:23-26.

4. Moini M, Rezaishiraz H, Zafarghandi MR: Characteristics and outcome of injured patients treated in urban trauma centers in Iran. J Trauma 2000, 48:503-7.

5. Duane TM, Rao RI, Aboutanous MB, Wolfe LG, Malhotra AK: Are trauma patients better off in a trauma ICU? J Emerg Trauma, Shock 2008, 1:74-7.

6. Abubakar AS, Ojo EO, El-Nafaty AU, Edomwonyi NP: An audit of one-year intensive care practice in a developing country. The Internet Journal of Anesthesiology 2008, 18:2

7. Mitchell VT, Scarlett MD, Amata AV: Trauma Admissions to the ICU of the University Hospital of the West Indies, Kingston, Jamaica. Trauma Care Fall/Winter 2001, 86-89.

8. Amanor-Boadu SD, Sanusi AA, Oyeleke SO, Soyannwo O: A: Intensive Care for Trauma Victims in a Developing Country: Priorities and Challenges for Improvement. Afr J Trauma 2003, 1:51-53.

9. Bastos PC, Knaus WA, Zimmermann J: The importance of technology for achieving superior outcome from intensive care. Brazil APACHE III study group. Intensive Care Med 1996, 22:664-669.

10. Nakamura T, Nishimura M, Okada Y: Evaluation of mortality of patients admitted to ICU for the last 12 years. Masui 1999, 48:1332-6. 
11. Chalya PL, Mabula JB, Ngayomela IH, Kanumba ES, Chandika AB, Giiti G, Mawala B, Balumuka DD: Motorcycle injuries as an emerging public health problem in Mwanza City, north-western Tanzania. Tanzania Journal of Health Research 2010, 12:214-221.

12. Chalfin DB, Trzeciak S, Likourezos A, Baumann BM, Dellinger RP: Delayed study group: Impact of delayed transfer of critically ill patients from the emergency department to the intensive care unit. Crit Care Med 2007, 35:1477-1483.

13. Young MP, Gooder VJ, McBride K, James B, Fisher ES: Inpatient transfers to the intensive care unit: Delays are associated with increased mortality and morbidity. J Gen Intern Med 2003, 18:77-83.

14. Pronovost PJ, Angus DC, Dorman T, Robinson KA, Dremsizov TT, Young TL: Physician staffing patterns and clinical outcomes in critically ill patients: a systematic review. JAMA 2002, 288:2151-2162.

15. Multz AS, Chalfin DB, Samson IM, Dantzker DR, Fein AM, Steinberg HN, Niederman MS, Scharf SM: A "closed" medical intensive care unit (MICU) improves resource utilization when compared with an "open" MICU. Am J Respir Crit Care Med 1998, 157:1468-1473.

16. Thorens JB, Kaelin RM, Jolliet P, Chevrolet JC: Influence of the quality of nursing on the duration of weaning from mechanical ventilation in patients with chronic obstructive pulmonary disease. Crit Care Med 1995, 23:1807-1815.

17. Size M, Borgstein ES, Haisma $\mathrm{HJ}$ : One year audit of admission to the Intensive Care Unit of the Queen Elizabeth Central Hospital, Blantyre. Malawi Med J 2005, 17(1):12-14

18. Harding-Goldson HE, Crandon IW, MCDonald AH, Augier R, FearonBoothe D, Rhoden A, Meeks-Aitken N: Surgical and Intensive Care needs of Head-injured Patients Transferred to the University Hospital of the West Indies. West Indian Med J 2007, 56(3):230-234.

19. Oyegunle AO, Oyegunle VA: The Intensive Care Unit in a Young Nigeria Teaching Hospital: The Sagamu (1994-1997) Experience - A retrospective study. Afr J Anaesth Int Care 1997, 3:41-43.

20. Adenekan AT, Faponle AF: Trauma Admissions to the ICU of a Tertiary Hospital in a Low Resource Setting. African Journal of Anaesthesia and Intensive Care 2009, 9(2):5-7.

21. Byrick RJ, Caskennette GM: Audit of critical care: aims, uses, costs and limitations of a Canadian system. Can J Anaesth 1992, 39:260-9.

doi:10.1186/1757-7241-19-61

Cite this article as: Chalya et al:: Trauma admissions to the Intensive care unit at a reference hospital in Northwestern Tanzania. Scandinavian Journal of Trauma, Resuscitation and Emergency Medicine 2011 19:61.

\section{Submit your next manuscript to BioMed Central and take full advantage of:}

- Convenient online submission

- Thorough peer review

- No space constraints or color figure charges

- Immediate publication on acceptance

- Inclusion in PubMed, CAS, Scopus and Google Scholar

- Research which is freely available for redistribution

Submit your manuscript at www.biomedcentral.com/submit
Biomed Central 